\title{
O EFEITO DE DIFERENTES TIPOS DE CONSEQUÊNCIAS CULTURAIS NA SELEÇÃO DE CULTURANTES
}

\section{EFFECTS OF DIFFERENT KINDS OF CULTURAL CONSEQUENCES ON CULTURAL SELECTION}

\author{
FÁBIO HENRIQUE BAIA \\ FELIPE FERNANDES AZEVEDO \\ SAULo MendonÇa SEgantini \\ RAFAEL PERES MACEDO \\ UNIVERSIDADE DE RIO VERDE, BRASIL \\ LAÉRCIA ABREU VASCONCELOS \\ UNIVERSIDADE DE BRASÍLIA, BRASIL
}

\begin{abstract}
RESUMO
Investigou-se o uso de consequências individuais e culturais de diferentes tipos na determinação da seleção de culturantes em metacontingências. Participaram do estudo 18 universitários distribuídos em dois grupos: Grupo Bens para Si (GBS) e Grupo Bens para Outros (GBO). Cada grupo foi composto por oito gerações. Cada geração foi composta por duplas. Ao fim de cada geração o participante mais antigo deixava o experimento e era substituído por novo membro ingênuo. O GBS recebeu consequências individuais (CI) e consequências culturais (CC) trocáveis por dinheiro. O GBO recebeu CI trocáveis por fotocópias, e CC trocáveis por materiais escolares doáveis a um projeto social. Havia duas fases: na Fase Aquisição CI e CC estavam disponíveis. Na Fase Extinção a geração 7 foi exposta apenas à CI sem CC e na geração 8, não havia CI nem CC. Os resultados indicam que a seleção de operantes e culturantes na Fase Aquisição ocorreu de modo similar em ambos os grupos. Na Fase Extinção nota-se maior sensibilidade do GBO à retirada das CC. Esses resultados sugerem que o uso de CI e CC de diferentes tipos influenciam na manutenção de culturantes. Discute-se as implicações dos resultados para o conceito de metacontingência.
\end{abstract}

Palavras-Chave: consequências culturais, consequências individuais, metacontingências, seleção cultural

\begin{abstract}
We investigated the use of individual and cultural consequences of different types in the selection of culturants in metacontingencies. The study included 18 students divided into two groups: Group Goods for Oneself (GBS) and Group Goods for Others (GBO). Each group was composed of eight generations and each generation consisted of dyads. After each generation the oldest participant left the experiment and was replaced by a new naive member. GBS received individual consequences (IC) and cultural consequences (CC) exchangeable for cash. GBO received IC exchangeable for photocopies, and $\mathrm{CC}$ exchangeable for school supplies to donate to a social project. There were two phases: in Acquisition Phase IC and CC were available. In Extinction Phase, generation 7 was exposed only to CI without CC, and for generation 8 received neither IC or CC. The selection of operants and culturants in Acquisition Phase was similarly for both groups. In Extinction Phase, GBO showed greater sensitivity to the withdrawal of CC. These results indicate that the use of different types of stimuli as IC and CC influence the maintenance of culturants. We discuss the implications of the results for the metacontingency concept.
\end{abstract}

Key words: cultural consequences; individual consequences; metacontingency; cultural selection; culturants.

Os autores agradecem ao CNPq e a UniRV por fomentar parcialmente esta pesquisa com incentivos de Iniciação Científica nos anos de 2013-2014 e 2014-2015. Correspondência relativa a este artigo deve ser enviada a Fábio Henrique Baia. Universidade de Rio Verde (UniRV). Faculdade de Psicologia, Fazenda Fontes do Saber, Campus Universitário, Rio Verde, Goiás CEP.: 75901-970, Cx. Postal 104. E-mail: fabio@unirv.edu.br 
O terceiro nível de seleção tem recebido atenção por parte dos analistas do comportamento (Andery, Micheletto, \& Sério, 2005; Sampaio \& Andery, 2010; Skinner, 1953, 1981, 1987). Diversos conceitos e processos foram propostos para a compreensão da seleção do comportamento no nível cultural, por exemplo, comportamento social, produção agregada, macrocontingências e metacontingências. A partir de Glenn (1986, 1988), foram iniciadas investigações que utilizaram o conceito de metacontingência para a compreensão da seleção de práticas culturais. Atualmente o conceito descreve uma relação contingente entre contingências comportamentais entrelaçadas (CCEs), produtos agregados e consequências culturais (Glenn \& Malott, 2004; Martone \& Todorov, 2007).

Hunter (2012) sugere que as CCEs e seus produtos agregados (PA) selecionados em metacontingências sejam nomeados de culturantes. Os produtos agregados são subsequentes a respostas e possuem como característica o fato de serem necessariamente produzidos por respostas de mais de uma pessoa, além da impossibilidade de serem produzidos individualmente (Sampaio \& Andery, 2010; Vichi \& Tourinho, 2012). As consequências culturais, por sua vez, são contingentes às CCEs e seus PAs (Glenn \& Malott, 2004; Vichi, Andery e Glenn, 2009), de modo que comportamentos operantes não são capazes de gerar tais consequências. A distinção entre produto agregado e consequências culturais, pode ser caracterizada pelo fato de que em metacontingências o produto agregado é apenas um efeito ambiental, que não necessariamente retroage selecionado os culturantes ${ }^{1}$, enquanto a consequência cultural (CC) é um evento ambiental contingente a CCEs e seus produtos agregados e necessariamente retroage selecionado culturantes. Apesar de não ter função retroativa, o produto agregado é necessário para a compreensão de seleção de CCEs em metacontingências, pois é por meio dele que se atende ao critério ambiental, resultando na liberação das consequências culturais (Malott \& Glenn, 2006; Todorov, 2012).

Portanto, a metacontingência não é o alargamento de contingências operantes, mas uma unidade distinta (Glenn, 2004), dado que na contingência operante a resposta é selecionada, enquanto na metacontingência o culturante é selecionado. Desse modo, os operantes são parte integrante do que é analisado em uma metacontingência, mas não a unidade de seleção. É necessário destacar que as consequências culturais são distintas das consequências operantes. Assim, a identificação e diferenciação de consequências individuais e consequências culturais permite a análise da seleção de operantes e culturantes por diferentes eventos ambientais.

Em estudos que investigam a seleção de culturantes em laboratório, a utilização de consequências individuais e culturais de diferentes tipos pode auxiliar na análise da seleção de operantes e culturantes

1 Há outras situações nas quais um PA pode retroagir selecionando CCEs, como em agriculturas de subsistência. Porém, esses casos são distintos de metacontingências. separadamente. A utilização de consequências individuais e culturais de mesmo tipo pode propiciar um efeito redundante das consequências manipuladas.

Consequências são de diferentes tipos quando apresentam distinções entre suas propriedades físicas (e.g., dinheiro versus vale-compras), funcionais (reforçador positivo ou estímulo aversivo) ou conceitual (reforçador primário versus reforçador secundário). Uma possibilidade de diferenciar tipos de reforçadores pode ser estabelecida em função dos conceitos de bem pessoal e bem para outros (Abib, 2001; Skinner, 1971). Por um lado, quando a consequência produzida é um reforçador positivo para o comportamento de quem emite a resposta, considera-se esse evento reforçador como "bem pessoal" (Dittrich, 2003). Por outro lado, "bem para outros" se caracteriza por situações nas quais a resposta emitida por um organismo produz consequências reforçadoras positivas para o comportamento de outro organismo, ou ainda, quando um organismo produz reforçadores negativos para outrem (Dittrich \& Abib, 2004).

Diversos estudos têm investigado experimentalmente a seleção de culturantes (e.g., Pereira, 2008; Vichi, Andery \& Glenn, 2009; Caldas, 2009; Alfaix-Melo, Souza \& Baia, 2010; Costa, Nogueira \& Vasconcelos, 2012; Marques, 2012). Há diversidade no emprego de consequências individuais (CI) e consequências culturais entre estudos experimentais de metacontingências. Bullerjhann (2009) utilizou CI e CC de mesmo tipo (físico e funcional), isto é, as consequências eram caraterizadas por acréscimo de pontos e bônus trocáveis por dinheiro ao fim da participação. O objetivo de Bullerjhann (2009) foi investigar a seleção de culturantes em função da apresentação de CC em laboratório. A tarefa foi realizada em computadores. Havia até quatro participantes desempenhando a tarefa individualmente, cada participante em um terminal de computador. No inicio de um ciclo, o computador apresentava quatro estímulos numéricos. O participante deveria inserir números nas caselas vazias abaixo de cada um dos estímulos numéricos. O computador realizava a soma do estímulo numérico e o número inserido na casela abaixo, porém o resultado não era exibido na tela para o participante. $\mathrm{O}$ critério para liberação de CI exigia que as quatro somas entre estímulos numéricos e números inseridos resultasse em números ímpares. As CC tiveram como critério a comparação entre as somas dos números inseridos pelo participante no ciclo. Assim, o produto agregado que produzia a liberação de CC (i.e., bônus) era a soma $(\Sigma)$ do participante $1(\mathrm{P} 1)$ maior ou igual $(\geq) \Sigma \mathrm{P} 2 \geq$ $\Sigma \mathrm{P} 3 \geq \Sigma \mathrm{P} 4$

Bullerjhann (2009) realizou dois experimentos. O Experimento 1 investigou se o tamanho do grupo, isto é, o número de membros em uma geração $(n=4)$ poderia afetar a seleção de culturantes. Inicialmente dois participantes desempenhavam a tarefa e após estabilidade (i.e., produção de CCES e produtos agregados que atendessem o critério ambiental em pelo menos $80 \%$ das tentativas, sendo as quatro últimas consecutivas) novos participantes eram inseridos individualmente na situação experimental, até que a geração fosse constituída de quatro membros. 
Após a formação de geração com quatro membros, a experimentadora substituía participantes para investigar se essa troca afetaria a prática cultural estabelecida. Os resultados indicaram que houve seleção de culturantes. A produção agregada ocorreu de acordo com as exigências ambientais, ainda que em alguns ciclos tenha sido observado que os participantes continuaram a produzir PAs que geravam CC, mesmo quando os comportamentos envolvidos nas CCEs não produziam CI. O número de participantes e a substituição não afetou as práticas culturais estabelecidas. O Experimento 2 foi realizado com apenas dois participantes (sem nenhuma história anterior com a tarefa experimental) e sem que CCs estivessem disponíveis. O objetivo foi investigar se a produção agregada observada no Experimento 1 foi realmente contingente às CCs. Os resultados indicam que o PA elegido como critério para liberação de CC no Experimento 1 também foi produzido no Experimento 2, ainda que nenhuma CC fosse contingente a essa produção. Mesmo com a substituição de participantes, o PA continuou a ser produzido em vários ciclos.

Os resultados do trabalho de Bullerjhann (2009) levantam, por um lado, a questão de que um padrão de comportamentos operantes pode ser mantido apenas pelas CCs, mesmo quando CIs não são produzidas (cf. Experimento 1), talvez porque tais comportamentos operantes também eram contingentes às CCs. Por outro lado, as relações estabelecidas em CCE podem ser suficientes para manter o PA, mesmo quando CCs não são contingentes. A utilização de consequências individuais e culturais do mesmo tipo na investigação dos efeitos selecionadores de operantes e culturantes pode produzir um fenômeno mais próximo de uma situação de cooperação do que de metacontingência. Por isso, outros estudos têm utilizado consequências individuais e culturais de diferentes tipos.

Saconatto e Andery (2013) também investigaram a seleção de culturantes em laboratório. No estudo CI e $\mathrm{CC}$, caracterizadas por pontos e bônus, também foram trocadas por dinheiro ao fim da participação. Os autores utilizaram CI e CC de mesmo tipo físico (i.e, pontos e bônus eram trocados por dinheiro), porém diferente de Bullherjhann (2009), em Saconatto e Andery as CI e CC eram caracterizadas por evitar a perda de pontos e bônus. A tarefa foi a mesma de Bullerjhann (2009). Os resultados obtidos indicaram que comportamentos que produziam CI foram emitidos desde a primeira geração, na maior parte dos ciclos. Porém, os culturantes que produziam PA que evitava a perda de pontos tornou-se mais frequente apenas durante a sexta geração. A produção de culturantes cujo PA atendia ao critério para evitar perda de bônus continuou sendo emitido em quase todos os ciclos na sétima, oitava e nona gerações. Saconatto e Andery (2013) programaram duas gerações nas quais nenhum culturante evitaria perda de bônus; essa manipulação objetivou investigar se na ausência de $\mathrm{CC}$ a prática cultural estabelecida nas fases anteriores seria mantida. Assim, a décima e décima primeira gerações foram expostas a essa manipulação. $\mathrm{Na}$ ausência de $\mathrm{CC}$ contingentes a produção agregada tornou-se pouco frequente nos ciclos, o que indica que a relação contingente entre culturantes e $\mathrm{CC}$ foi determinante para a seleção cultural observada nas gerações anteriores. Esse resultado é distinto do encontrado por Bullerjhann (2009), Experimento 2. Uma possibilidade é que os diferentes tipos de CI e CC empregados entre os estudos pode ter contribuído para os resultados encontrados.

Cavalcanti, Leite e Tourinho (2014) utilizaram CI e $\mathrm{CC}$ de diferentes tipos (em termos de propriedades físicas). CI eram fichas trocáveis por dinheiro, enquanto as CC eram itens escolares para doação. A tarefa experimental envolveu uma matriz de dez linhas (nomeadas com números de 1 a 10) e dez colunas (nomeadas com letras de A a J). Cada linha possuía um preenchimento de cores, havendo um total de cinco cores diferentes. Cada cor preenchia duas linhas no total. Se o participante escolhesse linhas de números ímpares, uma ficha trocável por dinheiro (CI) era liberada. As CI tiveram seu critério de produção mantido o mesmo durante os dois experimentos. As CC dependiam de diferentes sequências de cores formadas pela escolha de cada linha dos quatro participantes. Quando o critério para a produção de CC era atendido, um item escolar era disponibilizado para doação a crianças assistidas por um projeto social. A exigência de conjunto de cores variou entre as condições do estudo.

O Experimento 1 de Cavalcanti et al. (2014) investigou o efeito de aproximações sucessivas com o aumento gradual de complexidade ambiental (i.e., quantidade de exigências ambientais a serem atendidas para que o culturante produzisse CC). Participaram do experimento quatro estudantes universitários. Havia diferentes condições: linha de base LB - condição na qual as CI estavam disponíveis e maior exigência ambiental para produção de $\mathrm{CC}$ - e condição AS, subdividida em quatro condições (AS1, AS2, AS3 e AS4). Quanto maior o número da condição AS, maior a complexidade ambiental (i.e., mais especificada era a sequência de cores a ser formada), sendo que AS4 tinha os mesmos critérios que a Linha de Base. $O$ critério de estabilidade para a condição AS foi produção de CC em pelo menos $80 \%$ dos últimos 20 ciclos. Os resultados mostraram que a produção de CI ocorreu desde os primeiros ciclos e continuou a ocorrer em alta frequência em todas as condições. Os culturantes não foram produzidos na LB, e durante a condição AS1 as CC passaram a ser produzidas em quase todas as tentativas. Nas condições AS2, A3 e A4 também foi observada a produção de $\mathrm{CC}$, ainda que as exigências ambientais fossem cada vez mais complexas. Os autores concluíram que o procedimento de aproximações sucessivas foi efetivo para estabelecimento de culturantes com maior complexidade ambiental para produção de CC.

O Experimento 2 de Cavalcanti et al. (2014) investigou o efeito do procedimento de aproximações sucessivas na seleção de culturantes envolvendo aumento gradual concomitante de complexidade ambiental e complexidade de componente - relacionado ao número de componentes presentes nas CCEs. $\mathrm{O}$ experimento iniciou com dois participantes; à medida que o critério de estabilidade (mesmo do Experimento 1) era atendido, um 
novo participante era adicionado ao grupo. Foi programada a participação de até quatro participantes. A entrada de um novo participante aumentava a complexidade de componente - já que mais comportamentos eram envolvidos nas CCEs - e a complexidade ambiental - já que o critério para produção de CC estava relacionado a escolhas das cores da linha dos demais participantes. Os resultados mostraram que a produção de CI ocorreu em alta frequência desde a linha de base, porém com a entrada do terceiro participante houve alguns momentos em que as CI não eram produzidas por todos os participantes. Já a produção de CC exigiu muitas tentativas até que o critério de estabilidade fosse atingido com dois participantes. Com a entrada do terceiro participante, o experimento foi encerrado sem que o critério de estabilidade fosse atendido. Isto é, as $\mathrm{CC}$ não foram produzidas, a despeito de sua disponibilidade e a utilização do procedimento de aproximações sucessivas. Os autores discutem que a dificuldade de produção de CC pode ter ocorrido em função do tipo de critério ambiental utilizado, já que exigia do participante responder ao ciclo atual e, ao mesmo tempo, escolher linhas distintas das escolhidas no ciclo anterior.

Outro estudo a investigar experimentalmente metacontingências foi realizado por Sampaio et al. (2013). O estudo utilizou CI e CC do mesmo tipo físico e funcional (acréscimo de pontos e bônus em contadores individuais), porém diferente dos estudos anteriores, as consequências não eram trocadas por outros eventos ambientais, como dinheiro ou material escolar. Participaram do estudo 12 universitários divididos em quatro tríades. A tarefa envolvia a escolha individual dos participantes por figuras compostas de diferentes quantidades de setas após a apresentação de um figura modelo. O critério para liberação de CI era a escolha de uma figura com no máximo uma seta a menos do que a quantidade de setas da figura modelo. A liberação de CC dependia da posição (ângulo) das setas impressas na figura escolhida pelos participantes. Por exemplo, as setas da figura escolhida pelo participante B deveria diferir em aos menos $60^{\circ}$ das setas da figura escolhida pelo participante $\mathrm{A}$, assim como as setas da figura escolhida pelo participante $\mathrm{C}$ deveriam diferir em $60^{\circ}$ das setas da figura escolhida pelo participante B. Havia dois critérios para produtos agregados que produziam diferentes magnitudes de CC. O critério parcial era composto por produtos agregados nos quais apenas dois dos três participantes escolhiam figuras que atendiam ao critério de liberação de CC (400 bônus). O Critério Total exigia PA caracterizado por três figuras que atendiam a exigência de posição das setas acima mencionado e geravam 900 bônus.

Sampaio et al. (2013) programaram três fases. A fase linha de base foi caracteriza pela disponibilidade apenas das CI. A segunda fase foi caracterizada pela disponibilidade de produção de CI e CC, sendo exigido, além da diferença de posição, que as setas estivessem orientadas em sentido horário. A terceira fase foi similar à segunda, porém as setas deveriam estar orientadas em sentido anti-horário para produção de CC. Além das manipulações das exigências ambientais, o estudo contou com a manipulação da possibilidade de interação verbal. Três das quatro tríades tinham permissão para conversar durante a realização da tarefa. A quarta tríade foi proibida de se comunicar durante o desempenho da tarefa. Observou-se que na fase de linha de base todas as tríades produziam CI acima da linha do acaso, isto é, em mais de $50 \%$ das tentativas, mas a produção de CC tendeu a ocorrer abaixo da linha do acaso na primeira fase. No começo da segunda fase as tríades com permissão de comunicação produziam PA que atendiam ao critério parcial em maior frequência do que PA que atendiam ao critério total. Porém ao longo dessa fase a produção de PAs que atendiam ao critério total se tornou frequente. Já a tríade que não tinha permissão de comunicação foi capaz de produzir apenas PAs parciais na segunda-fase. Apenas as Tríades 2 e 3 atenderam ao critério de estabilidade e foram expostas à terceira fase. Ambas as tríades produziram resultados similares: a produção de PA parcial no início da fase e a produção de PA total ao final.

Os autores concluíram que os resultados sugerem que houve seleção de culturantes e que essa seleção é facilitada pela interação verbal. Além disso, o estudo apresentou uma nova tarefa experimental para investigação de metacontingências. Outro dado relevante é que, apesar dos pontos e bônus não serem trocados por dinheiro, o desempenho dos participantes parece ter sido controlado por estes eventos ambientais.

Como descrito anteriormente, estudos que investigam seleção de culturantes por metacontingências têm utilizado diferentes relações entre CI e CC, no que se refere ao tipo de consequências. Nota-se que apesar das diferenças, os resultados são similares, indicando que a seleção de operantes ocorre mesmo a despeito da diversidade no uso de diferentes tipos de consequências. Porém, nenhum estudo manipulou a diferença entre tipos de CI e CC. A pergunta que dirigiu este trabalho foi " o que aconteceria se em uma investigação experimental de seleção por metacontingências fossem utilizados diferentes tipos de CI e CC?" Seriam os resultados distintos daqueles obtidos em estudos anteriores? Até o momento nenhum estudo havia avaliado potenciais efeitos do uso de diferentes tipos de CI e CC comparando o desempenho obtido utilizando os mesmos parâmetros de procedimento, variando apenas o tipo de consequências. Estudos experimentais de metacontingências têm utilizado diferentes procedimentos. Bullerjhann (2009) e Saconatto e Andery (2010) utilizaram o procedimento META de inserção números. Cavalcanti et al (2014) utilizaram o procedimento da matriz, enquanto Sampaio et al. (2014) utilizaram o procedimento das figuras modelo e comparação. O uso de diferentes procedimentos dificulta a comparação dos resultados no que se refere a possíveis efeitos do uso de diferentes tipos de consequências.

Alguns estudos investigaram o uso de diferentes tipos de consequências na seleção e manutenção de operantes isolados. Por exemplo, Costa et al. (2008) 
investigaram se o tipo (em termos de propriedades físicas) de reforçador utilizado poderia exercer algum efeito no desempenho de humanos em esquemas de reforçamento de intervalo fixo (FI), após história de reforçamento em razão fixa (FR) ou reforçamento diferencial de taxas baixas (DRL). Os participantes expostos a FR apresentaram taxas altas, enquanto os participantes expostos ao DRL apresentaram taxas baixas de respostas, mesmo quando o tipo de reforçadores foi diferente para cada grupo. Entretanto, quando expostos a FI, o tipo de reforçador produziu diferentes efeitos. Os grupos com história de reforçamento com esquemas FR produziram taxas de respostas mais baixas ao longo das sessões de FI. Porém, participantes que recebiam como consequências pontos virtuais apresentaram maior pausa pós-reforço do que a observada no desempenho dos participantes que recebiam dinheiro ou fotocópias. Em relação aos participantes com história prévia em DRL, os resultados em FI indicam que houve aumento na taxa de respostas, independente da qualidade de reforçador empregado. Assim, no nível operante a utilização de diferentes tipos de reforços produz diferentes efeitos na determinação do comportamento em determinadas mudanças nas contingências (de FR para FI e de DRL para FI). Os efeitos de história com diferentes tipos de consequências culturais ainda não foram investigados em estudos de metacontingências.

Em relação à natureza das consequências, Weiner (1977) realizou um estudo que comparou o desempenho do responder quando os reforçadores empregados eram caracterizados como ganhos para si, versus produção de ganhos para outro. Assim, CI de diferentes tipos foram empregadas. Em todos os seis experimentos a tarefa foi a mesma. Em geral, os participantes sentavam em frente à mesa em que havia três botões com os seguintes rótulos: (1) doar; (2) pontos ou (3) ganhar. Desse modo, os participantes poderiam produzir ganhos monetários para um parceiro (doar), produzir pontos para si (pontos) e produzir ganhos monetários para si (ganhar). Os participantes foram informados de que havia um parceiro que desempenharia a tarefa simultaneamente, em outra parte do prédio. No Experimento 5, o parceiro era um confederado. Ao longo dos experimentos as respostas para produção de ganhos (i.e., dinheiro) estavam sob esquema FR40. Em alguns experimentos foi permitido aos participantes produzir pontos não trocáveis por dinheiro sob um esquema FR10. O conteúdo das instruções variou entre os experimentos. O Experimento 1 investigou se o comportamento de doar é um operante, ou seja, um comportamento que depende de suas consequências. Além disso, também se objetivou comparar a taxa de respostas de doar e ganhar. Foi utilizado um delineamento com quatro grupos, os quais podiam emitir apenas as respostas de doar. Um grupo poderia emitir apenas respostas de: (1) doar dinheiro; (2) ganhar dinheiro; (3) doar pontos; (4) produzir pontos (não trocáveis por dinheiro) e (5) ganhar e produzir pontos.
As instruções foram as mesmas para todos os grupos e informavam aos participantes que eles poderiam doar dinheiro para o parceiro, ganhar dinheiro ou produzir pontos para si, porém esses pontos não poderiam ser trocados por dinheiro e até não responder. A instrução declarava o esquema envolvido apenas para produção de pontos, isto é, a exigência de 10 respostas no botão pontos. E ainda, que haveria uma luz acima dos botões indicando a disponibilidade para responder. Os resultados do Experimento 1 demonstram que a taxa de respostas do grupo doar foi menor do que a taxa de respostas do grupo ganhar. Já o grupo doar ou produzir pontos apresentou taxas com menores índices para produzir pontos do que doar. O grupo com produção de ganhos ou pontos apresentou taxas de respostas de ganhar muito maiores. O comportamento de doar é um comportamento operante, já que as taxas de doar, apesar de menores do que as taxas do comportamento de ganhar foram maiores do que as taxas dos comportamentos de produzir pontos para si. Portanto, a diferença entre doar e ganhar é produzida quando há uma relação de concorrência com a resposta de produzir pontos. A diferença entre as taxas de ganhar e de produzir pontos foi muito maior do que a diferença entre doar e produzir pontos.

O Experimento 2 avaliou as relações entre as propriedades dos reforços de doar a outros e as taxas de respostas durante extinção e recondicionamento. Dois participantes poderiam apenas doar e os outros dois, apenas ganhar. Durante a fase de extinção a luz acima do botão (operandum) permanecia acesa e na fase de recondicionamento, as instruções eram novamente lidas. As taxas de doar foram menores do que as taxas de ganhar. Durante a fase extinção ambas as taxas diminuíram, porém como o autor utilizou medidas absolutas, é difícil comparar a resistência à mudança de cada taxa. Com o recondicionamento, o responder foi mais consistente para respostas de ganhar do que doar, com altas taxas estáveis de ganhar e variação do doar, com taxas caindo em algumas sessões e aumentando na última sessão.

O Experimento 4 replicou o Experimento 1 com delineamento intra-sujeito. Três grupos com 10 sujeitos cada foram utilizados. Os resultados mostram que na Fase 1, um total de 23 participantes apresentaram taxas altas para o comportamento de ganhar dinheiro e taxas baixas para produzir pontos não trocáveis por dinheiro. Na Fase 2, as respostas de doar dinheiro, ganhar dinheiro e ganhar e doar dinheiro expostas à extinção apresentaram queda em suas taxas, enquanto as respostas de produzir pontos (que não estavam sob extinção) permaneceram com taxas inalteradas. Ademais, ocorreu também aumento na taxa da outra resposta não exposta à extinção, isto é, ganhar pontos para o Grupo 1 e doar pontos para o Grupo 2 . Novamente, na Fase 3 todos os grupos emitiram maiores taxas de respostas de ganhar. Portanto, produzir ganhos financeiros ou doações financeiras são eventos com maior propriedade reforçadora do que produzir pontos para si. Wiener (1977) sugeriu que o 
tipo de consequências é variável determinante para a produção de diferentes efeitos sobre o responder.

Apesar dos estudos que investigaram os efeitos do uso de diferentes tipos de reforçadores sobre o comportamento operante, ainda não há um estudo que tenha por objetivo investigar o efeito de diferentes tipos de consequências na investigação de metacontingências em laboratório. Assim, o objetivo deste estudo foi avaliar se diferentes tipos de CI e CC produziriam diferentes efeitos na aquisição de operantes e culturantes. Além disso também se investigou se durante a quebra da relação contingente entre operantes e CI, e culturantes e CC haveria diferentes efeitos em função dos diferentes tipos de consequências empregadas. Para buscar responder a estas perguntas, foram comparadas as linhagens culturais de dois grupos, um no qual foram utilizadas consequências individuais e culturais caracterizadas por pontos e bônus trocáveis por dinheiro, e outro, no qual foram utilizadas CIs classificadas como bens para si (pontos trocáveis por fotocópias) e CCs como bens para o outro (pontos trocáveis por materiais escolares).

\section{MÉTODO}

\section{Participantes}

Este estudo empregou um total de 18 estudantes universitários. Os participantes eram de ambos os sexos e foram divididos em dois grupos (Bens para $\mathrm{Si}$ e Bens para Outros). Os grupos foram compostos por oito gerações, cada geração formada por dois membros.

\section{Material}

O experimento foi realizado no Laboratório de Psicologia Experimental da Universidade de Rio Verde (UniRV). Neste laboratório havia duas salas com mesas e cadeiras. Foram utilizados três notebooks, filmadora, gravador digital, duas mesas, três cadeiras, materiais escolares (canetas, cadernos, borrachas, lápis, canetas de colorir, tesouras sem ponta, cadernos de caligrafia, colas e réguas), 1.000 fotocópias e R\$232,00 em dinheiro.

\section{Procedimento}

Os participantes eram recebidos na sala de espera, na qual assinavam o Termo de Consentimento Livre e Esclarecido (TCLE) em que constava a aprovação do Comitê de Ética (Protocolo114/2010). Após a assinatura, os participantes desempenhavam uma tarefa pré-experimental que avaliava competência para desenvolver operações matemáticas de adição, e classificar números como ímpares ou pares. O critério de acerto de pelo menos $80 \%$ das operações matemáticas e a classificação dos números foram utilizados como critério de inclusão.

\section{Descrição Geral da Tarefa}

A tela dos computadores apresentava dois quadrantes, cada um correspondendo a um dos participantes. Cada quadrante era composto por quatro estímulos numéricos, quatro quadrados vazios, um botão "OK", contadores de somas, pontos e bônus. Os quadrados vazios eram alinhados verticalmente (colunas) aos estímulos numéricos; nestes o participante poderia adicionar números entre 0 e 9 e para alterar a inserção de números entre os quadrados vazios, o participante clicava com o mouse no quadrado onde desejava inserir o número ou pressionava as teclas de setas.

Este experimento utilizou o procedimento de tentativas discretas. No início de cada tentativa o computador apresentava os quatro estímulos numéricos. Os participantes inseriam os números nos quadrados vazios e manipulando o mouse clicavam em OK. Em seguida, o computador apresentava as consequências individuais, e, quando programadas, as consequências culturais. Em seguida, se iniciava um intervalo entre tentativas (ITI) de $7 \mathrm{~s}$.

Foram utilizados os seguintes critérios para produção de consequências: Para consequências individuais, caso as quatro somas, uma por coluna, produzidas entre o estímulo numérico e número inserido resultasse em número ímpar, o computador apresentava: (1) um som, (2) estímulos visuais compostos pelo valor da magnitude do reforço positivo (ver Tabela 1) precedido pelo símbolo $+($ p.ex., +100$)$ e (3) acréscimo do valor da magnitude no contador de pontos. Se ao menos uma das quatro somas produzidas resultasse em número par, então o computador apresentava: (1) realce em amarelo do estímulo numérico, (2) um som distinto daquele apresentado aos reforços positivos, (3) valor da magnitude de retirada de pontos precedido pelo símbolo - (e.g., - 10) e (4) a retirada do valor da magnitude no contador de pontos.

Para as consequências culturais, o critério ambiental externo para a produção de bônus foi a soma dos números inseridos pelo participante recente maior ou igual do que a soma dos números inseridos pelo participante antigo. A comparação entre as somas dos números inseridos pelos participantes caracterizou o produto agregado. Quando os produtos agregados atendiam ao critério ambiental externo, a consequência cultural era caracteriza por: (1) um som, (2) estímulos visuais compostos por apresentação do valor da magnitude precedido pelo símbolo + (e.g., +600) e acréscimo da metade do valor da magnitude no contador de bônus. Produtos agregados, que não atendessem ao critério, tinham como consequência: (1) som e (2) apresentação do número zero precedido pelo símbolo + (e.g., +0) durante 8 s. A apresentação das consequências caracterizava o fim da tentativa seguida por um intervalo entre tentativas (ITI) de $7 \mathrm{~s}$, durante o qual, os quadrantes tinham seus tamanhos diminuídos, com mouse e teclado inoperantes. 
Tabela 1.

Magnitudes das Consequências Individuais (CI) e Consequências Culturais (CC) por Grupo

\begin{tabular}{|c|c|c|c|c|}
\hline \multirow[t]{2}{*}{ Grupos } & \multicolumn{2}{|c|}{ Consequências Individuais } & \multicolumn{2}{|c|}{ Consequências Culturais } \\
\hline & Reforço Positivo & $\begin{array}{c}\text { Punição } \\
\text { Negativa }\end{array}$ & $\begin{array}{l}\text { Atendimento do } \\
\text { critério }\end{array}$ & Não atendimento \\
\hline Bens para $\mathrm{Si}$ & +300 & -30 & +600 & 0 \\
\hline Bens para Outros & +300 & -30 & +600 & 0 \\
\hline
\end{tabular}

A tentativa se encerrava quando o computador apresentava as consequências. Se na tentativa anterior houvesse ocorrido acerto operante, o computador inseria novos algarismos em todos os quadrantes. Porém, se ocorresse erro, o computador reapresentava os algarismos nas mesmas células da tentativa anterior, com as bordas das células de erro com realce amarelo. Acertos e erros culturais na tentativa anterior não produziram apresentação de diferentes eventos na tentativa subsequente.

\section{Delineamento Experimental}

Cada geração (dupla de participantes) correspondeu a uma sessão experimental. Apenas a Geração 1 foi divida em duas etapas. Na primeira, um participante desempenhou sozinho a tarefa, sem que consequências culturais estivessem disponíveis. No início dessa etapa um experimentador lia instruções mínimas que informavam como operar o programa de computador por meio de mouse e teclado, a troca de pontos e bônus por material escolar ou fotocópias e o aviso do computador quanto ao encerramento da etapa.

A primeira etapa se encerrava quando o participante produzia: (1) mínimo de 20 tentativas com ao menos $80 \%$ de reforços positivos nas 10 últimas, tendo as quatro últimas tentativas a produção de reforços consecutivos, ou (2) no máximo 50 tentativas realizadas. Após o encerramento da primeira etapa, iniciava-se a segunda etapa da primeira geração. Nesta, um novo participante ingênuo era inserido à situação. Nessa segunda etapa os dois participantes desempenhavam a tarefa em conjunto. Ao iniciar a segunda etapa, um experimentador lia novas instruções sobre a apresentação dos participantes, a troca de pontos e bônus por materiais escolares e fotocópias, e a possibilidade de interação verbal durante a participação. O critério para encerramento dessa etapa e de todas as gerações foi: (1) realização de no mínimo 20 tentativas, sendo que nas 10 últimas pelo menos $80 \%$ das tentativas tivessem produção de bônus e com as quatro últimas produções de bônus sendo consecutivas, ou (2) no máximo 50 tentativas.
Ao final da sessão o computador informava qual participante deveria deixar o experimento para que um novo membro o substituísse. O critério para substituição foi o maior tempo de contato com a tarefa. Foi estabelecido um total de oito gerações por grupo.

Como pode ser notado na Tabela 2, a Fase Aquisição foi caracterizada pela apresentação contingente das consequências individuais e consequências culturais. Da primeira à sexta geração, operantes e culturantes produziam consequências de modo contingente. No entanto, a Fase Extinção foi caracterizada pela suspensão das consequências individuais (geração 7) e CI e CC (geração 8). A sétima geração foi exposta apenas à suspensão das consequências individuais. Portanto, operantes não produziam consequências, ou seja, independente das somas por coluna resultarem em números pares ou ímpares, nenhum estímulo era apresentado. Porém, culturantes que atendiam ao critério ambiental externo para produção de bônus continuaram a produzir bônus. A oitava geração foi exposta à suspensão das consequências individuais e consequências culturais e o critério para encerramento foi a realização de 50 tentativas.

Tabela 2

Delineamento Experimental por Fases, Programação de Consequências e Gerações

\begin{tabular}{ccc}
\hline Fases & $\begin{array}{c}\text { Consequências } \\
\text { Programadas }\end{array}$ & $\begin{array}{c}\text { Geração } \\
\text { Exposta }\end{array}$ \\
\hline Aquisição & $\begin{array}{c}\text { Consequências } \\
\text { individuais e } \\
\text { consequências } \\
\text { culturais }\end{array}$ & $1^{\mathrm{a}}$ à $6^{\mathrm{a}}$ \\
\hline Extinção & $\begin{array}{c}\text { Somente } \\
\text { Consequências } \\
\text { culturais } \\
\text { Nenhuma } \\
\text { consequência }\end{array}$ & $7^{\mathrm{a}}$ \\
\hline
\end{tabular}


Tabela 3 .

Descrição dos Grupos, Tipos de Consequências Individuais e Consequências Culturais

\begin{tabular}{|c|c|c|c|c|}
\hline \multirow[t]{2}{*}{ Grupo } & \multicolumn{2}{|c|}{ Consequências Individuais } & \multicolumn{2}{|c|}{ Consequências Culturais } \\
\hline & Qualidade & $\begin{array}{l}\text { Natureza do } \\
\text { bem }\end{array}$ & Qualidade & Natureza \\
\hline Bens para $\mathrm{Si}$ & Dinheiro & Para $\mathrm{Si}$ & Dinheiro & Para Si \\
\hline Bens Para Outros & Fotocópia & Para Si & $\begin{array}{l}\text { Material } \\
\text { Escolar }\end{array}$ & Para Outros \\
\hline
\end{tabular}

Tabela 4.

Operantes e culturantes que atendiam ao critério para produção de consequências por participantes de cada grupo e geração

\begin{tabular}{|c|c|c|c|c|c|}
\hline Grupo & Participante & Geração & $\begin{array}{c}\text { Total de } \\
\text { Tentativas }\end{array}$ & Operantes & Culturantes \\
\hline \multirow{17}{*}{$\begin{array}{c}\text { Grupo Bens } \\
\text { para } \mathrm{Si}\end{array}$} & P1 & & 20 & 16 & \\
\hline & \multirow{3}{*}{$\mathrm{P} 2$} & 1 & 22 & 21 & 14 \\
\hline & & 1 & 22 & 21 & 14 \\
\hline & & 2 & 21 & 20 & 18 \\
\hline & \multirow[t]{2}{*}{ P3 } & 2 & 21 & 20 & 18 \\
\hline & & 3 & 20 & 20 & 17 \\
\hline & \multirow[t]{2}{*}{ P4 } & 3 & 20 & 20 & 17 \\
\hline & & 4 & 20 & 20 & 20 \\
\hline & \multirow[t]{2}{*}{ P5 } & 4 & 20 & 20 & 20 \\
\hline & & 5 & 23 & 23 & 22 \\
\hline & \multirow[t]{2}{*}{ P6 } & 5 & 23 & 23 & 22 \\
\hline & & 6 & 20 & 20 & 20 \\
\hline & \multirow[t]{2}{*}{ P7 } & 6 & 20 & 20 & 20 \\
\hline & & 7 & 20 & 19 & 20 \\
\hline & \multirow[t]{2}{*}{ P8 } & 7 & 20 & 19 & 20 \\
\hline & & 8 & 50 & 49 & 47 \\
\hline & P9 & 8 & 50 & 50 & 47 \\
\hline & \multirow[t]{2}{*}{$\mathrm{P} 11$} & & 20 & 15 & \\
\hline & & 1 & 20 & 17 & 17 \\
\hline & \multirow[t]{2}{*}{$\mathrm{P} 12$} & 1 & 20 & 18 & 17 \\
\hline & & 2 & 20 & 20 & 18 \\
\hline & \multirow[t]{2}{*}{ P13 } & 2 & 20 & 16 & 18 \\
\hline & & 3 & 20 & 18 & 17 \\
\hline \multirow{11}{*}{$\begin{array}{l}\text { Grupo Bens } \\
\text { para Outros }\end{array}$} & \multirow[t]{2}{*}{ P14 } & 3 & 20 & 16 & 17 \\
\hline & & 4 & 31 & 27 & 21 \\
\hline & \multirow[t]{2}{*}{ P15 } & 4 & 31 & 26 & 21 \\
\hline & & 5 & 20 & 18 & 15 \\
\hline & \multirow[t]{2}{*}{ P16 } & 5 & 20 & 17 & 15 \\
\hline & & 6 & 20 & 20 & 20 \\
\hline & \multirow[t]{2}{*}{ P17 } & 6 & 20 & 19 & 20 \\
\hline & & 7 & 20 & 19 & 19 \\
\hline & \multirow[t]{2}{*}{ P18 } & 7 & 20 & 18 & 19 \\
\hline & & 8 & 50 & 49 & 29 \\
\hline & P19 & 8 & 50 & 43 & 29 \\
\hline
\end{tabular}




\section{Manipulação dos tipos de consequências}

O Grupo Bens para Si e o Grupo Bens para Outros ao final de suas participações tinham respectivamente, as consequências culturais trocadas por dinheiro ou por material escolar. A Tabela 3 apresenta as informações referentes aos tipos de consequências individuais $\mathrm{e}$ consequências culturais. As consequências individuais e consequências culturais trocáveis por dinheiro e fotocópia foram definidas como bens para si em função de que essas consequências eram destinadas ao próprio participante que produziu pontos e bônus. As consequências culturais trocáveis por materiais escolares foram definidas como bens para outros, pois esses materiais eram doados a crianças carentes participantes de um projeto de extensão da Universidade.

Os resultados mostraram que não houve diferença na seleção de operantes e culturantes em função dos diferentes tipos de CI e CC programadas. Porém, na Fase Extinção o uso de diferentes tipos de consequências teve efeito diferencial entre os grupos. Enquanto o GBS não apresentou alteração no padrão de produção de culturantes estabelecido na Fase Aquisição, o GBO apresentou maior sensibilidade à quebra da relação contingente entre culturantes e CC (geração 8), pois foi possível notar maior variação no tipo de PA produzido.

A Tabela 4 apresenta os operantes e culturantes que atendiam ao critério para produção de consequências por participantes de cada grupo e geração. É possível notar que todos os participantes do GBS emitiram operantes e produziram culturantes em quase todas as tentativas. Em todos os casos operantes que atendiam ao critério ocorreram em mais de $85 \%$ das tentativas. Já os culturantes ocorreram no mínimo em $63 \%$ das tentativas (geração 1), ou seja acima da linha do acaso. Esse resultado sugere que operantes e culturantes foram selecionados pelas consequências contingentes, assim como observado anteriormente por Bullerjhann (2009) - Experimento 1, Cavalcanti et al (2014), e Sampaio et al. (2013). Mesmo com a suspensão de consequências (Gerações 7 e 8), os participantes continuaram a emitir operantes e a produzir culturantes que atendiam aos critérios utilizados em gerações anteriores para liberação de CI e CC, respectivamente. Bullerjhann (2009) encontrou resultado similar em seu Experimento 2, pois mesmo na ausência de CC contingentes, foi observada a produção agregada que atendia ao critério ambiental para liberação das $\mathrm{CC}$ no Experimento 1, em que tais consequências eram contingentes ao PA.

Uma possibilidade explicativa é a complexidade ambiental. Complexidade ambiental é definida por Glenn e Malott (2004) como variáveis externas as CCEs; quanto mais numerosas as exigências ambientais a serem atendidas para a liberação de $\mathrm{CC}$, mais complexo é o fenômeno. Nesse sentido, no presente estudo havia apenas três possibilidade de produção agregada, sendo que duas destas eram elegíveis para liberação de CC. Portanto, mesmo com a quebra da relação contingente entre culturante e $\mathrm{CC}$, era de se esperar que os culturantes fossem mantidos. Assim, a baixa complexidade ambiental utilizada neste estudo pode ter sido responsável pelo obtido. Cavalcanti et al. (2014) e
Sampaio et al. (2013) manipularam a complexidade ambiental e observaram que os culturantes tendiam a ocorrer em função da complexidade exigida. No estudo de Cavalcanti et al. (2014) mesmo culturantes envolvidos em alta complexidade ambiental foram produzidos após o uso de aproximações sucessivas.

Ainda na Tabela 4 é possível observar que durante a Fase de Aquisição (Gerações 1 a 6) do GBO, os resultados são similares aos dos GBS. Em relação a operantes, a menor porcentagem encontrada foi de $67 \%$ das tentativas nas quais o operante atendia ao critério ambiental. Os culturantes, por sua vez, ocorreram em no mínimo 67\% (Geração 4). A diferença entre os grupos pode ser observada quando as CI e CC não estavam disponíveis (Geração 8 do GBO). Neste grupo, em 50 tentativas, apenas em 29 os culturantes eram elegíveis de produzirem $\mathrm{CC}$ nas gerações anteriores. É possível que essa variação na produção de culturantes tenha ocorrido em função do tipo de consequências programadas para o grupo. As CC no GBO eram trocáveis por material escolar doáveis a um programa de extensão universitária. Apesar de ter investigado apenas no nível individual, Weiner (1997) Experimento 2, observou que sob extinção operante, respostas de doar foram mais sensíveis a quebra da contingência do que respostas de produzir ganhos para si. É possível então que os resultados observados neste estudo em nível cultural tenham relação com o tipo de consequência empregada. O GBS não apresentou sensibilidade à extinção em nível cultural.

A Figura 1 apresenta o registro cumulativo de operantes e culturantes que atendiam ao critério para produção de consequências em um registro acumulado para os Grupos Bens para si e Grupo Bens para Outros, nas Fases Aquisição e Extinção. Durante a Fase Aquisição, é possível notar que a emissão de operantes que produziam CI foi praticamente contínua (i.e., sem interrupções) em todas as gerações do Grupo Bens para Si. No Grupo Bens para Outros a emissão de operantes foi constante, porém é possível notar que em algumas gerações (G2 e G4), o desempenho apresentou maior variação, especialmente para os participantes recentes. É possível que o participante que havia sido inserido recentemente na tarefa tivesse demandado instruções sobre como responder, e que o participante com maior história experimental estivesse oferecendo modelo de como responder. Porém, como os dados das verbalizações não foram analisados, não é possível afirmar se essa interpretação é correta. Além disso, no caso da Geração 4 do GBO, os participantes produziram CI em mais de $87 \%$ das tentativas. Porém, como o critério de estabilidade exigia no mínimo $80 \%$ de produção de CC nas 10 últimas tentativas, sendo essa produção consecutiva nas quatro últimas, houve maior quantidade de tentativas nesta geração. Apesar dos participantes produzirem culturantes que atendiam o critério em muitas tentativas, essa produção não foi suficiente para atendimento do critério, o que acarretou em mais tentativas do que as demais gerações.

Em relação ao culturante, os resultados sugerem que para o GBS, a produção de culturantes que atendiam ao critério para liberação de $\mathrm{CC}$ ocorreram com frequência desde a Geração 1, na qual das 22 tentativas, em 14 foram 
produzidas CCs. Nas gerações seguintes, que foram expostas à Fase Aquisição, as CC continuaram a ser produzidas em quase todas as tentativas; das cinco gerações seguintes (G2, G4, G5, G6), em quatro as CC foram produzidas em mais de $95 \%$ das tentativas. O GBO também produziu resultados similares na Fase Aquisição, porém com menor porcentagem; das seis gerações, apenas duas (G2 e G6) produziram CC em mais de $90 \%$ das tentativas. Esses dados sugerem que as programações foram efetivas para seleção de culturantes. Os trabalhos de Caldas (2009), Vichi, Andery e Glenn (2009), Bullerjhan (2009), Sampaio et al (2013) e Cavalcanti et al. (2014) encontraram resultados similares.

Durante a Fase Extinção é possível notar na Figura 1, que o GBS manteve o desempenho apresentado na Fase Aquisição. Os operantes que produziam CI continuaram a ocorrer em índices superiores a 95\%, mesmo quando essas consequências estavam suspensas. Novamente, no GBO os resultados foram similares, porém com índices menores: em mais de $86 \%$ das tentativas foram emitidos operantes que atendiam ao critério para liberação de CI. É possível que as CC tenham mantido o desempenho operante na Geração 7 de ambos os grupos, já que tais consequências continuaram disponíveis. Porém, mesmo com a suspensão das $\mathrm{CC}$ na Geração 8, o desempenho foi mantido. Resultados similares foram encontrados por Caldas (2009) - Experimento 2. Naquele trabalho a suspensão das CI e CC também não produziu mudança na emissão de operantes e produção de culturantes. Desse modo, uma possível interpretação seria de que os participantes liberassem reforçadores outros não especificados pelas programações experimentais, como verbalizações, para persistirem no desempenho. Em Sampaio et al. (2013), a tríade que não possuía permissão de interagir verbalmente foi incapaz de atender o critério de estabilidade, o que sugere que o comportamento verbal facilita a seleção de culturantes, porém, não há na literatura referente à seleção cultural, estudos que esclareçam se essas verbalizações são suficientes para manter a produção de culturantes quando as CC estão suspensas.

\section{Grupo Bens para si}

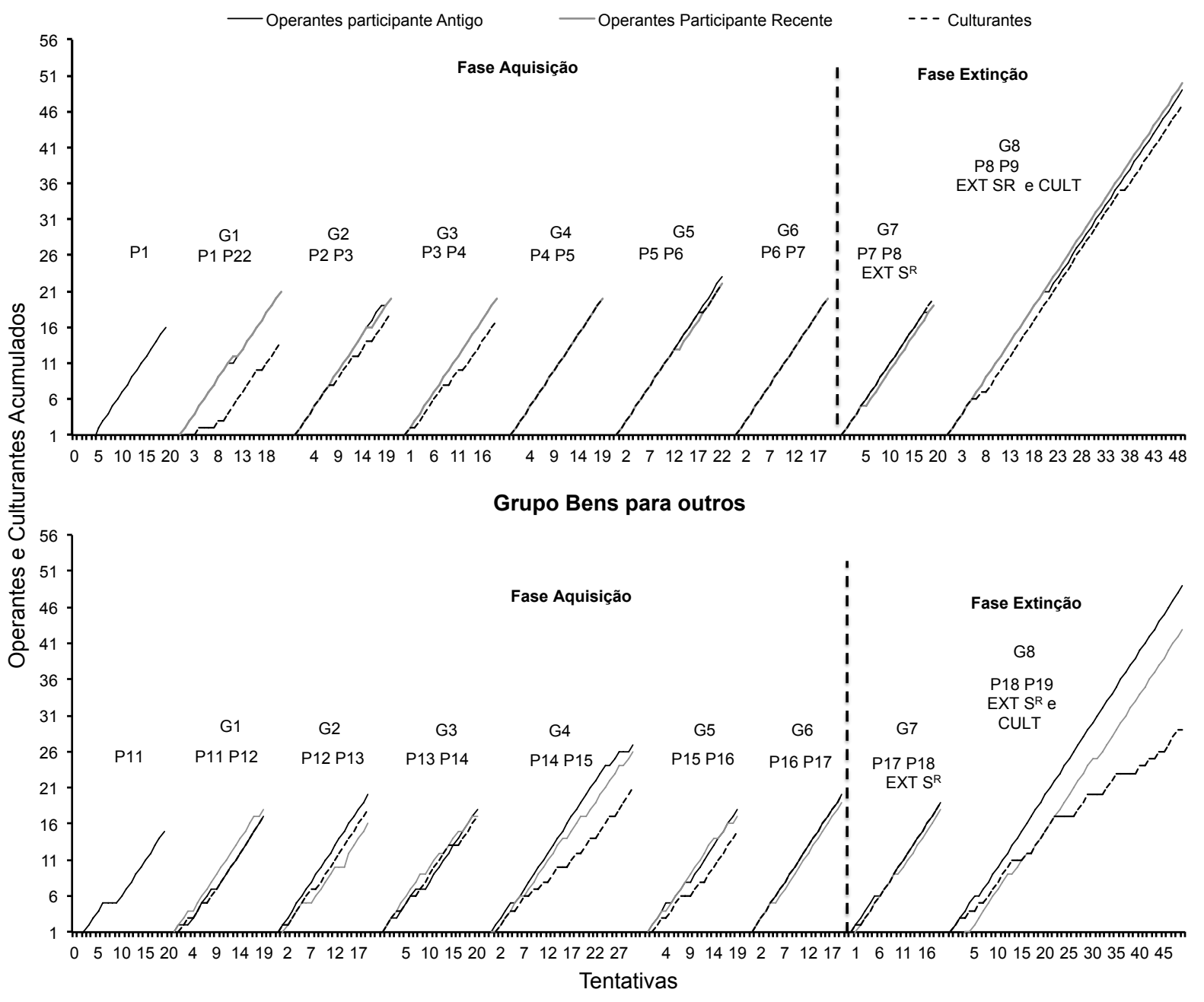

Figura 1. Registros acumulados de operantes e culturantes durante as fases de aquisição e extinção. Os operantes dos participantes antigos são apresentados nas linhas solidas pretas. Os operantes dos participantes recentes são apresentados nas linhas solidas cinza. Os culturantes são apresentados pelas linhas tracejadas. 
O Grupo Bens para Outros, por sua vez, sob extinção apresentou um padrão de culturantes diferente do Grupo Bens para Si. Quando as consequências individuais foram suspensas, não se nota qualquer mudança no padrão de respostas, porém na Geração 8 (G8), com a suspensão das consequências culturais muda-se o padrão de emissão de culturantes. Os culturantes que produziam a consequência cultural deixaram de ocorrer de modo consistente na ausência de consequências culturais.

A análise dos efeitos da ausência de consequências culturais pode também ser feita por meio dos produtos agregados gerados apresentados em uma geração. A Figura 2 apresenta a produção dos três tipos possíveis de produtos agregados. Os culturantes poderiam produzir produtos agregados por meio da soma dos números inseridos pelos participantes caso resultassem em: (1) soma do participante recente maior do que o participante antigo, (2) somas iguais (i.e., mesmo valor algébrico), e (3) soma do participante recente menor do que o participante antigo. Apenas os produtos do tipo 1 e 2 produziam consequências culturais do tipo bônus.

É possível observar na Figura 2 que durante a Fase Aquisição, tanto o Grupo Bens para Si quanto o Grupo Bens para Outros produziram consistentemente o produto agregado critério para liberação de consequências culturais. Entretanto, no Grupo Bens para Si houve variação durante a Fase de Aquisição entre os dois produtos que atendiam ao critério ambiental. Já o Grupo Bens para Outros produziu mais frequentemente o produto soma do participante recente maior do que a soma do participante antigo.

$\mathrm{Na}$ Fase Extinção nota-se, assim como observado na Figura 1, que a ausência de consequências individuais $(\mathrm{G} 7)$ ou consequências individuais e culturais (G8) não afetaram o desempenho do Grupo Bens para si. De forma diferente, o desempenho no Grupo Bens para Outros foi afetado com a suspensão das consequências individuais e culturais. Na Fase Extinção da Geração 8, observa-se variação entre os três tipos de produtos agregados possíveis, incluindo o único produto agregado que não atendia ao critério ambiental (i.e., soma do participante recente menor do que a soma do participante antigo) o qual torna-se a mais frequente ao final da geração. Outros estudos que realizaram uma fase de suspensão de CC também encontraram resultados nos quais a produção de culturantes apresentou pouca variação após a quebra da metacontingência. Caldas (2009) notou que a quebra da relação contingente entre culturantes e CC produziu pouca variação na produção de CCEs e seus produtos agregados. Bullerjhann (2009) Experimento 2, no qual não havia $\mathrm{CC}$ contingentes a culturantes, observou que a produção de CCEs e seus produtos agregados foi similar ao encontrado no Experimento 1, quando havia metacontingências. É possível que o uso de CI e CC de mesmo tipo atuem de modo redundante. Deste modo, mesmo com a quebra da relação contingente, a disponibilidade de uma das consequências é suficiente para manter operantes e culturantes. No caso da Geração 8, quando CI e CC estavam suspensas, é possível que a manutenção de operantes e culturantes tenha ocorrido em função do pouco contato com a quebra da relação contingente. Mais gerações deveriam ter sido expostas às programações de ausência de CI e CC, para verificar se ocorreria variação, isto é, respostas operantes e CCEs que não atendiam aos critérios para liberação de consequências exigidas nas fases anteriores.

Os resultados da Fase de Extinção sugerem ainda maior sensibilidade às metacontingências quando as consequências individuais e culturais são de diferentes tipos: o GBO apresentou maior variação na emissão de culturantes do que o GBS. Sendo assim, é possível sugerir que a utilização de CI e CC de diferentes tipos tenham contribuído para essa maior sensibilidade, isto é, o desempenho operante e a produção de culturantes acompanhou a mudança nas contingências e metacontingências. Essa afirmação está baseada nos dados observados e no fato de que pesquisas referentes a operantes encontraram resultados similares quando os efeitos de diferentes tipos de reforços foram comparados. Costa et al. (2008) obtiveram dados similares em nível operante. A utilização de diferentes tipos de consequências caracterizadas por pontos não trocáveis por dinheiro produziu maior sensibilidade comportamental, quando comparado à sensibilidade produzida por consequências como dinheiro ou fotocópias. Weiner (1977), por sua vez, demonstrou que no nível operante a produção de bens para os outros é um evento reforçador. $\mathrm{O}$ uso de reforçadores do tipo de bens para si, foram mais efetivos do que reforçadores do tipo bens para outros como observado no Experimento 4, Fases 1 e 3. É possível considerar que a variação no desempenho na fase Extinção do Grupo Bens para Outros tenha ocorrido pelo menor valor reforçador em contato com a ausência das consequências.

\section{CONCLUSÕES}

A utilização de diferentes tipos de CI e CC pode ser uma variável importante para estudos que investigam a seleção de culturantes. Diferente de outros trabalhos que empregaram CI e CC de mesmo tipo (e.g., Caldas, 2009) a utilização de CI diferente de CC parece ter contribuído para maior sensibilidade à mudança nas contingencias e metacontingências. Em futuras investigações certos cuidados metodológicos devem ser observados. Por exemplo, neste estudo foi empregado o uso de CI sempre do mesmo tipo como bem para si (GBS - dinheiro; e GBO - fotocópias). Seria interessante utilizar CI do mesmo tipo em relação ao tipo de bem e tipo físico do reforçador. O mesmo comentário é válido para CCs, que diferiram tanto em termos do tipo de bem (BSI - bens para si; e GBO - bem para outros) quanto em tipos físicos (CBS - dinheiro; e GBO - materiais escolares). Além disso, o exame das verbalizações pode auxiliar a responder a questões do porque comportamentos operantes e operantes continuaram a ser emitidos de modo similar a despeito da quebra de contingências. 


\section{Grupo Bens para si}

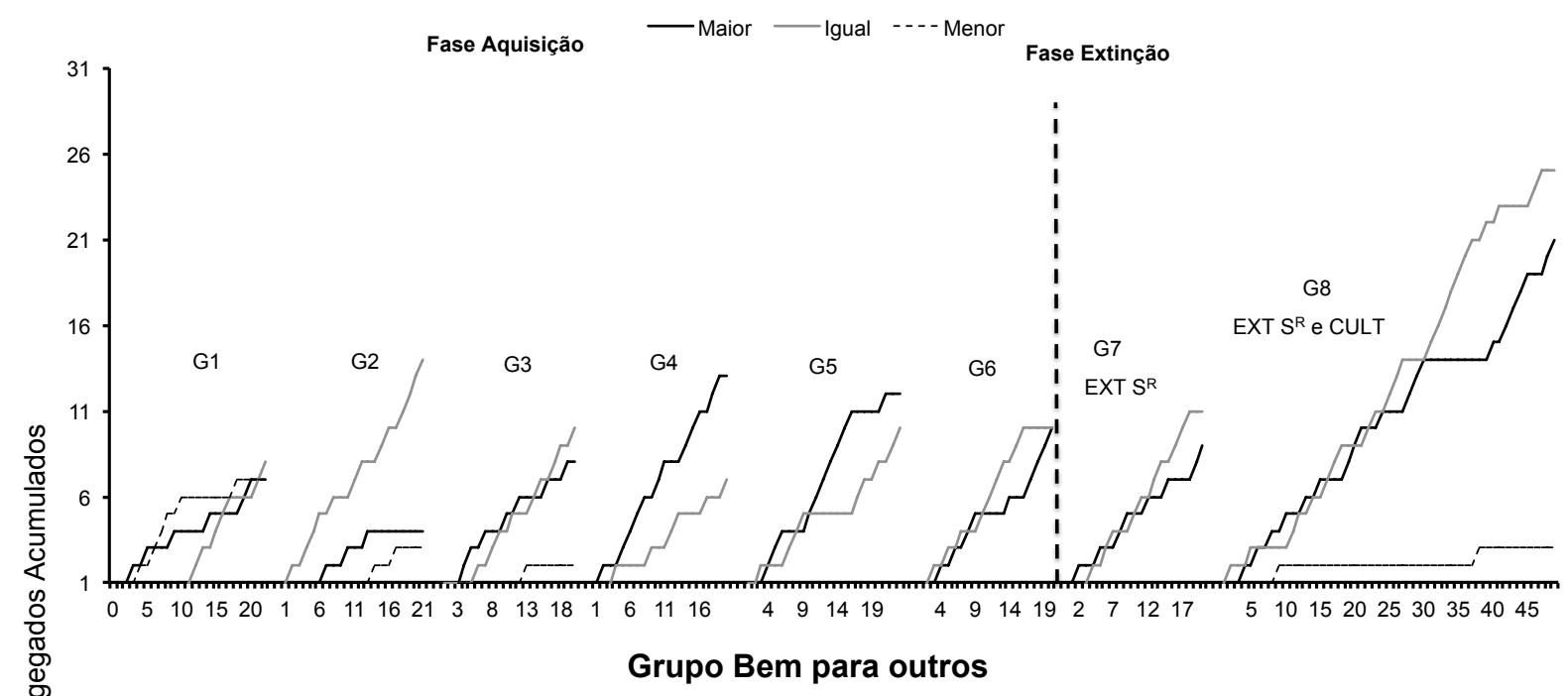

Fase Aquisição

Fase Extinção

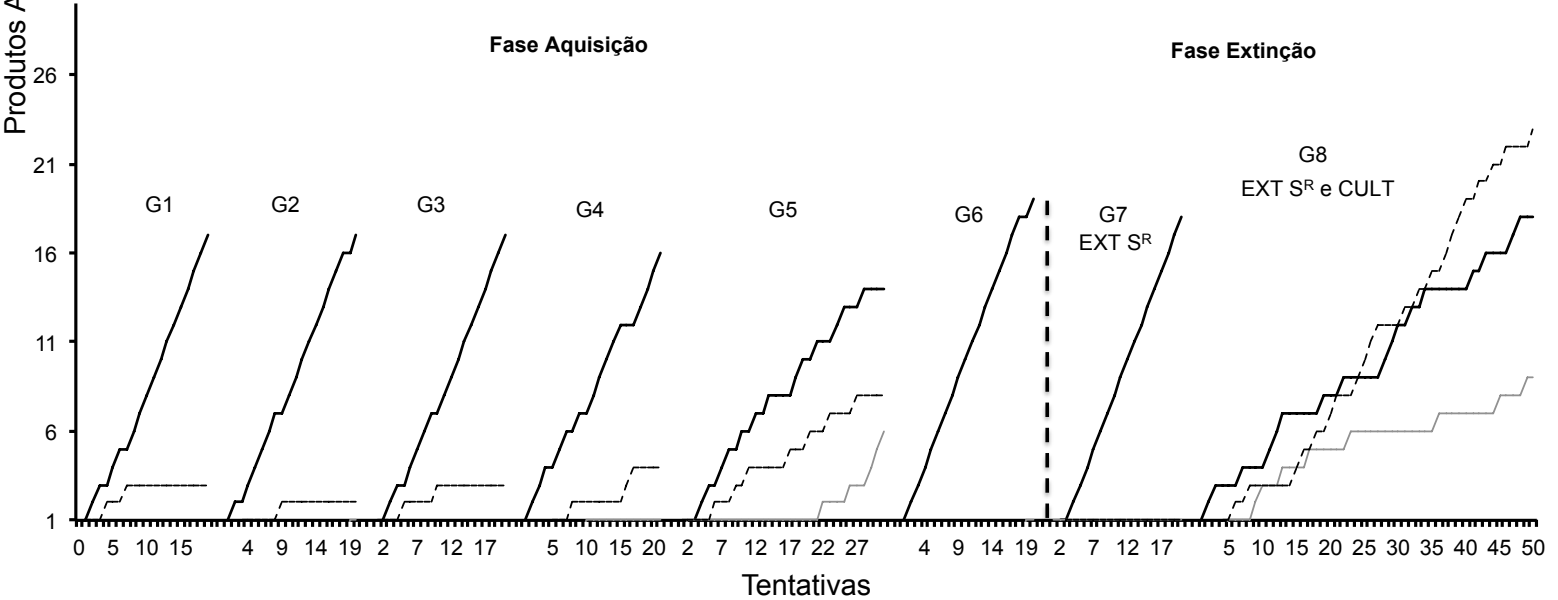

Figura 2. Registro acumulado dos três possíveis tipos de produtos agregados produzidos por culturantes de cada geração dos dois grupos. No painel superior são apresentados os dados do Grupo Bens para si. No painel inferior são apresentados os dados do Grupo Bem para outros. As linhas solidas pretas representam produtos agregados nos quais a soma dos números inseridos pelo participante mais recente foi maior do que a soma do participante antigo. Linhas sólidas cinza representam somas iguais de ambos os participantes. Linhas tracejadas indicam produtos agregados nos quais a soma do participante mais recente foi menor do que a do participante mais antigo.

O emprego do procedimento de inserção dos números (Pereira, 2008) possibilita comparação dos resultados em investigações de culturantes com a utilização do conceito de metacontingências. Reforços e consequências culturais produziram a seleção de operantes e culturantes, respectivamente. De modo geral, o estudo sugere que o uso de diferentes tipos de consequências não produz efeitos diferenciados na aquisição de operantes e culturantes. Porém, os resultados sugerem que há diferenças em culturantes sob extinção, a depender do tipo de consequência cultural utilizada.

Outro ponto a ser observado diz respeito à quantidade de PAs possíveis. Sugere-se que em estudos futuros no mínimo três participantes componham cada geração, para que mais de 18 tipos de PA sejam possíveis. Desse modo, sob extinção haverá maior quantidade de PAs a serem produzidos que não atenderiam ao critério ambiental utilizado na Fase Aquisição. Por fim, sugere-se que caso haja programação de quebra das contingências, que mais gerações sejam expostas, visto que neste estudo havia apenas duas gerações. E essa quantidade pode ser insuficiente para se observar alteração no padrão de operantes e culturantes.

\section{REFERÊNCIAS}

Abib, J. A. D. (2001). Teoria moral de Skinner e desenvolvimento humano. Psicologia: Reflexão $e$ Crítica, 14, 107-117.

Alfaix-Melo, M. A., Portilho de Souza, E., \& Baia, F. H. (2010). Metacontingências experimentais: avaliação do papel das consequências culturais sobre a seleção de culturantes. Psicologia IESB, 2, 1-21.

Andery, M. A. P. A., Micheletto, N., \& Sério, T. M. A. P. (2005). Análise de fenômenos sociais: esboçando uma 
proposta para a identificação de contingências entrelaçadas e metacontingências. Revista Brasileira de Análise do Comportamento, 1, 149-166.

Bullerjhann, P. B. (2009). Análogos experimentais de fenômenos sociais: o efeito das consequências culturais. Dissertação de Mestrado. São Paulo: Pontifícia Universidade Católica de São Paulo.

Caldas, R. A. (2009). Análogos experimentais de seleção e extinção de metacontingências. Dissertação de Mestrado. São Paulo: Pontifícia Católica de São Paulo.

Cavalcanti, D. E., Leite, F. L., \& Tourinho, E. Z. (2014). Seleção de práticas culturais complexas: avaliação experimental de um análogo do procedimento de aproximação sucessiva. Psicologia e Saber Social, 3, 2-21.

Costa, C. E., Banaco, R. A., Longarezi, D. M., Martins, E. V., Maciel, E. M., \& Sudo, C. H. (2008). Tipo de reforçador como variável moduladora dos efeitos de história em humanos. Psicologia Teoria e Pesquisa, 24, 251-262.

Costa, D., Nogueira, C. P. V., \& Vasconcelos, L. A. (2012). Effects of communication and cultural consequeces on choices combinations in PDG with four participants. Revista Latinoamericana de Psicología, 44, 121-131.

Dittrich, A. (2003). Introdução à filosofia moral skinneriana. Em C. E. Costa, J. C. Luzia, \& H. H. N. Sant'Ana (Orgs.), Primeiros passos em análise do comportamento e cognição (pp.11-24). Santo André: ESETec.

Dittrich, A., \& Abib, A. D. (2004). O sistema ético skinneriano e consequências para a prática dos analistas do comportamento. Psicologia: Reflexão e Crítica, 17, 427-433.

Glenn, S. S. (1986). Metacontingencies in Walden Two. Behavior Analysis and Social Action, 5, 2-8.

Glenn, S. S. (1988). Contingencies and metacontingencies: toward a synthesis of behavior analysis and cultural materialism. The Behavior Analyst, 11, 161-179.

Glenn, S. S. (2004). Individual behavior, culture and social change. The Behavior Analyst, 17, 133 - 151.

Glenn, S. S., \& Malott, M. E. (2004). Complexity and selection: implications for organizational change. Behavior and Social Issues, 13, 89-106.

Hunter, C. S. (2012). Analyzing behavioral and cultural selection contingencies. Revista Latinoamericana de Psicología, 44, 43-54.

Malott, M. E., \& Glenn, S. S. (2006). Targets of intervention in cultural and behavioral change. Behavior and Social Issues, 15, 31-56.

Marques, N. S. (2012). Efeitos da incontrolabilidade do evento cultural no estabelecimento e manutenção de práticas culturais: um modelo experimental de superstição. Dissertação de MestradoBelém, Pará: Universidade Federal do Pará.

Martone, R. C., \& Todorov, J. C. (2007). O desenvolvimento do conceito de metacontingência. Revista Brasileira de Análise do Comportamento, 3, 181-190.

Pereira, J. C. M. (2008). Investigação experimental de metacontingências: separação do produto agregado $e$ da consequência individual. Dissertação de Mestrado. São Paulo: Pontifícia Universidade Católica de São Paulo.

Saconatto, A. T., \& Andery, M.A.P.A. (2013). Seleção por metacontingências: um análogo experimental de reforçamento negativo. Interação em Psicologia, 17, 110.

Sampaio, A. A. S., \& Andery, M. A. P. A. (2010). Comportamento social, produção agregada e prática cultural: uma análise comportamental de fenômenos sociais. Psicologia: Teoria e Pesquisa, 26, 183-192.

Sampaio, A. A. S., Araújo, L. A. S., Gonçalo, M. E., Ferraz, J. C., Alves Filho, A. P., Brito, I. S., Barros, N. M., Calado, J. I. F. (2013). Exploring the role of verbal in a new experimental task for the study of metacontingencies. Behavior and Social Issues, 22, 87101.

Skinner, B. F. (1953) Science and Human Behavior. New York: The Free Press.

Skinner, B. F. (1971). Beyond freedom and dignity. New York: Alfred A. Knopf.

Skinner, B. F. (1981). Selection by Consequences. Science, 213, 501-504.

Skinner, B. F. (1987). Upon further reflexion. Englewoods Cliffs, NJ: Prentice Hall.

Todorov, J. C. (2012). Metacontingências e análise comportamental de práticas culturais. Clínica $e$ Cultura, 1, 36-45.

Vichi, C., \& Tourinho, E. Z. (2012). Consequências culturais $\mathrm{x}$ consequências comportamentais na literatura experimental de pequenos grupos. Acta Comportamentalia, 20, 201-215.

Vichi, C., Andery, M. A. P. A., \& Glenn, S. S. (2009). A metacontingency experiment: The effects of contingent consequences on patterns of interlocking contingencies of reinforcement. Behavior and Social Issues, 18, 4157.

Weiner, H. (1997). An operant analysis of human altruistic responding. Journal of the Experimental Analysis of Behavior, 27, 515-528. 